\title{
Vénus Khoury-Ghata poète, éd. J.-P. ZUBIATE
}

\section{Fabio Scotto}

\section{(2) OpenEdition \\ Journals}

\section{Edizione digitale}

URL: https://journals.openedition.org/studifrancesi/32288

DOI: 10.4000/studifrancesi.32288

ISSN: 2421-5856

\section{Editore}

Rosenberg \& Sellier

\section{Edizione cartacea}

Data di pubblicazione: 1 août 2020

Paginazione: 442

ISSN: 0039-2944

Notizia bibliografica digitale

Fabio Scotto, «Vénus Khoury-Ghata poète, éd. J.-P. zuBiATE», Studi Francesi [Online], 191 (LXIV | II) | 2020, online dal 01 septembre 2020, consultato il 18 septembre 2021. URL: http://journals.openedition.org/ studifrancesi/32288 ; DOI: https://doi.org/10.4000/studifrancesi.32288

Questo documento è stato generato automaticamente il 18 septembre 2021.

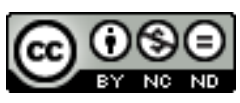

Studi Francesi è distribuita con Licenza Creative Commons Attribuzione - Non commerciale - Non opere derivate 4.0 Internazionale. 


\title{
Vénus Khoury-Ghata poète, éd. J.-P.
}

\section{ZUBIATE}

\author{
Fabio Scotto
}

\section{NOTIZIA}

Vénus Khoury-Ghata poète, éd. J.-P. zUBIATE, Toulouse, Presses Universitaires du Midi, 2019, "Littératures" 80, 163 pp.

1 La rivista universitaria "Littératures" dedica un ampio suo Dossier alla poetessa, narratrice e traduttrice libanese Vénus Khoury-Ghata, da tempo ritenuta una delle voci più alte e significative della letteratura francofona contemporanea. Nata a Pshery nel Libano settentrionale nel 1937, si è trasferita a Parigi nel 1972 e la sua vita è segnata, oltre che dal dramma della guerra nella sua patria natale, da alcuni lutti familiari quali la prematura morte del fratello e del marito. Da questi eventi deriva un'opera dai tratti intimi ed epici, fortemente ancorata alla memoria delle origini e dell'infanzia, capace di tensione civile e tesa alla difesa della dignità umana e dell'emancipazione femminile dall'inganno spesso insito nei radicalismi e nelle loro ideologie così tristemente attuali.

2 Nella sua Introduction (pp. 9-14), il curatore Jean-Pierre ZUBIATE sottolinea la molteplicità dei registri «épique, lyrique, élégiaque et même ludique» dell'opera dell'Autrice e la forte fisionomia della sua voce poetica ormai divenuta internazionalmente nota proprio in virtù di questo misto di carnalità e memoria intrisa di sussiego morale che si esprime attraverso uno stile frutto della sovrapposizione dell'arabo natale e del francese acquisito come lingua di formazione.

3 I dieci contributi affrontano i tratti più salienti dell'opera di Khoury-Ghata, dal tema del tragico e del dolore (Michèle FINCK, Isabelle $\mathrm{CHOL}_{\text {) }}$ al dramma della perdita (JeanPierre ZUBIATE) e alla mitica creazionista (Anne GoURIO), mentre altre letture affrontano nello specifico alcune raccolte poetiche recenti come Les mots étaient des loups (Paris, Gallimard, 2016) e Le Livre des suppliques (Paris, Mercure de France, 2015), la prima esaminata nei suoi aspetti elementali e cosmologici da Béatrice воNноммE, la seconda 
nell'indecidibilità dei limiti fra vivi e morti da Aude PRÉTA-DE BEAUfORT. Altri aspetti arricchiscono l'orizzonte critico di queste riflessioni, dalla trasversalità ricorrente del tema delle orties (Ortiche essendo, ad oggi, la sola raccolta poetica dell'A., da noi curata, tradotta in italiano, Rovigo, Il Ponte del Sale, 2007) trattato da Christine Dupouy e da Dominique CARLAT al singolare uso della «phrase-verset» nella prosa narrativa studiato da Samia KASSAB-CHARFI, fino alla poetica del dono presa in considerazione da Francesca TUMIA e Ines HORCHANI.

4 Concludono il Dossier alcuni Poèmes inediti (pp. 159-163) di Vénus Khoury-Ghata, densi di quel profondo senso di pietà del quale trasuda tutta la sua poesia. 